\title{
El propóleos, una Resina Biológica con Propiedades Curativas
}

\section{Propolis, a Biological Resin with Healing Properties}

\author{
Lipovka Yulia ${ }^{1 *}$, Alday Efraín¹, Velázquez Carlos ${ }^{1,2}$ \\ ${ }^{1}$ Departamento de Ciencias Químico Biológicas, Universidad de Sonora. Blvd. Luis Encinas y Rosales S/N. Hermosillo, Sonora 83000, México \\ ${ }^{2}$ Cuerpo Académico de Biología y Bioquímica, Departamento de Ciencias Químico Biológicas, Universidad de Sonora. Blvd. Luis Encinas y Rosales \\ S/N. Hermosillo, Sonora 83000, México.
}

Autor de correspondencia: Yulia Lipovka, PhD. E-mail: yulia.lipovka@unison.mx

\section{Resumen}

El propóleos, junto con la miel, la jalea real, la cera y el veneno de abejas, es considerado uno de los productos de colmena que ha generado gran interés por sus propiedades farmacológicas. El propóleos es una sustancia resinosa, elaborada por las abejas a partir de exudados, resinas y látex secretados por las hojas y brotes de plantas. Es una matriz biológica muy compleja, en la que se ha detectado la presencia de más de 500 sustancias químicas diferentes. Posee diversas propiedades biológicas, entre las cuales destaca su efecto anti-cancerígeno. Este artículo describe de una forma resumida los distintos productos de las abejas, poniendo énfasis en el propóleos y su composición química. Posteriormente, en el contexto de la biología del cáncer, se discuten los sucesos moleculares que subyacen el efecto anti-cancerígeno del propóleos, identificando las principales moléculas involucradas. Se describe la capacidad del propóleos de inhibir la proliferación, la progresión del ciclo celular y migración de células cancerígenas, así como de inducir apoptosis y suprimir la angiogénesis. El propóleos constituye una matriz biológica muy atractiva para el aislamiento de compuestos con actividad anti-cancerígena, que solos, o en conjunto, pudieran representar una alternativa para la elaboración de terapias contra el cáncer.

Palabras clave: propóleos, cáncer, propiedades antiproliferativas

\section{Abstract}

Propolis, along with honey, royal jelly, beeswax and bee venom, is a bee product that has drawn great attention due to its pharmacological properties. Propolis is a resinous substance made by bees from exudates, resins and latices secreted from leaves and leave buds of plants. It is a very complex biological matrix, with over 500 chemical constituents described to date. Propolis has different biological properties, anti-cancer activity being one of them. This article briefly describes the different types of bee products with a special focus on propolis and its chemical composition. Then, in the context of cancer biology, discusses the molecular events underlying the anti-cancer effects of propolis, identifying the key molecules involved. The effect of propolis on proliferation, cell cycle progression, apoptosis, migration of cancer cells and angiogenesis is reviewed. Propolis is a biological matrix with a great potential for isolation of chemicals with anti-cancer activity, which alone, or in combination, could represent an alternative for the development of new anti-cancer therapies.

Key words: propolis, cancer, antiproliferative propierties

DOI 10.46588/invurnus.v16i1.38

Recibido 21/10/2021

Aceptado 30/11/2021

Publicado 01/12/2021 


\section{Introducción}

Las abejas son insectos del orden Hymenoptera, y junto con otras especies (avispas, avispas, escarabajos, mariposas, polillas y moscas), así como ciertas aves, juegan un rol ecológico muy importante en la polinización natural de flores y plantas. Se estima que alrededor del $73 \%$ de todos los cultivos a nivel mundial son polinizados por abejas. Se piensa que en la actualidad existen entre 20 a 40 mil especies de abejas diferentes, aunque el número exacto está en disputa, mientras que la población de abejas a nivel mundial está en declive (Arbuckle et al. 2001). Entre las diferentes especies de abejas destaca la abeja de la miel (Apis mellifera), siendo uno de los insectos más domesticados.

La interacción del ser humano con las abejas data desde tiempos prehistóricos. Pinturas rupestres con antigüedad de 7,000 a 8,000 años muestran a cazadores de miel suspendidos en escaleras de cuerda, mientras cosechan miel de panales de abejas silvestres. Sin embargo, es hasta los años 3,000 antes de nuestra era que aparecen los primeros indicios de la apicultura, con construcciones de cavidades artificiales dentro de las cuales las abejas pueden construir su panal (Kritsky 2017). Además de la miel, las abejas elaboran otros productos naturales: polen (pan de abeja), jalea real, propóleos, cera y veneno; todos ellos químicamente diferentes y con un potencial terapéutico muy versátil.

La miel es producida por abejas obreras que recolectan néctar de flores y lo procesan mediante digestión y regurgitación repetida. Es una sustancia viscosa y azucarada que las abejas utilizan como fuente de alimentación, sobre todo en temporadas de escasez, como el invierno. La jalea real es una secreción de la hipofaringe de la abeja y de las glándulas salivales mandibulares. Se utiliza para alimentar a las larvas de las abejas obreras (hasta el tercer día solamente), a las larvas que se convertirán en abejas reinas, y constituye la comida exclusiva de la abeja reina a lo largo de su vida. El polen, mezclado con néctar y secreciones salivales de las abejas se convierte en pan de abeja, que constituye la fuente de alimentación principal del panal. Las abejas obreras producen cera con glándulas especializadas localizadas en la región abdominal, principalmente durante la fase de crecimiento de la colonia y a finales de la primavera, ya que ésta se utiliza para hacer panales. El veneno de abeja es un fluido complejo secretado por una glándula ubicada en la cavidad abdominal, e inyectado en las víctimas a través del aguijón (Cornara et al. 2017).

El propóleos es una sustancia de consistencia viscosa elaborada por las abejas. Lo utilizan para revestir sus panales, en parte gracias a sus propiedades antisépticas, asimismo, para el mantenimiento de la colmena debido a sus propiedades mecánicas (Simone-Finstrom y Spivak 2010). Desde hace miles de años, el ser humano se dio cuenta de las propiedades curativas del propóleos y lo empezó a emplear en la medicina tradicional. Desde hace algunas décadas, el propóleos ha sido objeto de estudio de científicos alrededor del mundo, que han ido descifrando los mecanismos biológicos detrás de sus propiedades curativas. En este artículo se discutirá el potencial biológico del propóleos producido por las abejas Apis mellifera, específicamente su efecto anti-cancerígeno, destacándose los principales mecanismos responsables de inhibir el crecimiento y la diseminación del cáncer.

\section{Propóleos de la Abeja Apis mellifera: Composición Química y Actividad Biológica}

El propóleos es una sustancia resinosa elaborada por diferentes especies de abejas (entre ellas las abejas recolectoras de miel del género Apis mellifera) a partir de exudados, resinas y látex secretados por las hojas, 
flores y brotes de plantas. Estas sustancias son procesadas mediante las enzimas salivales de las abejas, sufriendo modificaciones químicas menores y resultando en una matriz biológica compleja que conocemos como propóleos. En cuanto a proporciones, el propóleos se compone por 50\% resinas vegetales, $30 \%$ ceras de abeja, $10 \%$ aceites esenciales y aromáticos, $5 \%$ polen y el $5 \%$ restante corresponde a otras sustancias orgánicas (Huang et al., 2014).

La composición química del propóleos de las abejas Apis mellifera es muy variada, y depende en gran medida de las fuentes botánicas disponibles, la estación del año en la que ocurre la recolección, el tipo de clima y la región geográfica. Las abejas muestran preferencia por ciertas especies de plantas y pueden viajar hasta un máximo de $14 \mathrm{~km}$ de distancia para recolectar néctar, polen y resinas ricas en fitoquímicos bioactivos (Ratnieks y Shackleton 2015). A la fecha se han identificado más de 500 sustancias químicas en muestras de propóleos alrededor del mundo (Huang et al., 2014). Entre ellas abundan ácidos fenólicos y sus esteres, flavonoides, terpenos, aldehídos aromáticos, alcoholes, ácidos grasos, entre otros. Junto con el vino, el propóleos se ha declarado como una de las matrices biológicas más ricas en polifenoles (Medic-Saric et al., 2009).

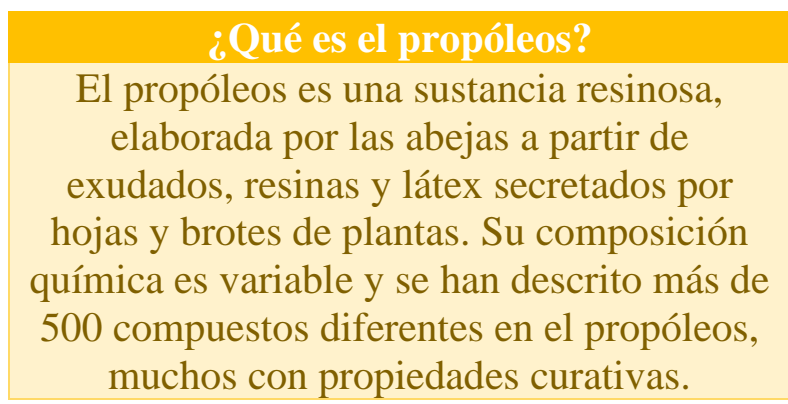

Las abejas utilizan el propóleos como una sustancia aséptica, revistiendo sus panales y así protegiéndolos del crecimiento de bacterias y hongos (Huang et al., 2014). Además, esta capa protectora sirve para mantener una homeostasis dentro del panal, controlando la temperatura, humedad y creando una barrera contra otros organismos invasores. De hecho, el término propóleos proviene de las palabras griegas pro, que significa "en frente de" o "en defensa de" y polis, que significa "comunidad" o "ciudad", y hace referencia a una sustancia defensora de la colmena, que forma parte de la inmunidad social de las abejas. Pero ¿qué es la inmunidad social? A pesar de que las abejas tienen un sistema inmunitario propio, como individuos que conviven en colmenas con más de 50,000 habitantes, necesitan contar con medidas de higiene adicionales que les permitan protegerse contra microorganismos patógenos causantes de infecciones y prevenir brotes de enfermedades, esto constituye la inmunidad social. Uno de los mecanismos de inmunidad social de las abejas consiste en la recolección de resinas y exudados de plantas (principalmente de brotes de hojas) con diversas propiedades antimicrobianas, y elaboración del propóleos a partir de éstos (Simone-Finstrom y Spivak 2010). De esta manera, las abejas aprovechan el metabolismo secundario de las plantas, que les brinda compuestos con propiedades antibacterianas, antifúngicas, antiparasitarias, etc.

Desde tiempos muy antiguos el ser humano ha empleado el propóleos como un remedio natural. Existen registros de que los egipcios utilizaban el propóleos para embalsamar sus cadáveres, mientras que los griegos y los romanos, lo usaban como antiséptico y cicatrizante en el tratamiento de heridas, así como desinfectante bucal. Su uso se fue propagando por varias civilizaciones a lo largo de la historia; hay registros de que los árabes y persas también conocían el propóleos y lo empleaban en la medicina tradicional. Entre los siglos diecisiete y veinte hubo un auge en la popularidad del propóleos en Europa, gracias a sus propiedades anti- 
bacterianas (Castaldo y Capasso 2002). Actualmente, gracias a décadas de investigación, se sabe que el propóleos cuenta con un sinfín de propiedades biológicas que incluyen la antioxidante, antiinflamatoria, antibacteriana, antifúngica, antiparasitaria, antiviral, inmunomudolatoria y antiproliferativa (anticancerígena) (Castaldo y Capasso 2002; Kuropatnicki et al. 2013).

\section{Determinantes Moleculares del Cáncer}

El cáncer es una de las patologías más relevantes del siglo XXI. Tan sólo en el año 2020, a nivel mundial se registraron 19.3 millones de casos de cáncer nuevos, cobrando la vida de 10 millones de personas (Sung et al., 2021). A pesar de la existencia de terapias y medicamentos, la mayoría son tratamientos poco específicos y ocasionan daños colaterales a tejidos sanos. Es por eso que la búsqueda de medicamentos contra el cáncer aún continúa. Más de dos décadas de estudios enfocados en entender las propiedades anticancerígenas del propóleos han demostrado que éste inhibe el crecimiento de las células cancerígenas, mientras que no afecta la proliferación de células normales. Este fenómeno se ha descrito en células de cáncer de mama, de pulmón, colon, próstata, cervicouterino, entre otros. Para comprender los mecanismos detrás de este fenómeno, primero es necesario definir qué es cáncer.

Las células de nuestro cuerpo, al igual que nosotros, viven en una sociedad, en donde están conscientes de su entorno, se comunican entre ellas y constantemente están tomando decisiones en función de las características actuales del ambiente que las rodea. Por ejemplo, una célula no se va a dividir, si siente que no hay suficiente espacio para crear células nuevas. Una célula cancerígena, en cambio, es aquella que rompe las reglas de esta sociedad, y decide dividirse de manera descontrolada, es decir, ignorando las señales de alto que le envíen sus células vecinas. Adquiere esta conducta debido a mutaciones (alteraciones) en su código genético que se traducen en producción de proteínas aberrantes, o bien, en cantidades incorrectas. Estas proteínas modulan su conducta, haciendo que la célula tome una serie de decisiones potencialmente peligrosas para el organismo al cual pertenece. Inicialmente, esto desencadena la formación de un tumor primario, producto de un crecimiento descontrolado de células cancerígenas, y posteriormente, puede provocar la migración de células tumorales (metástasis), diseminando el cáncer por el resto del cuerpo. Es en esta última etapa, cuando el cáncer se vuelve especialmente difícil de erradicar (Alberts et al., 2008).

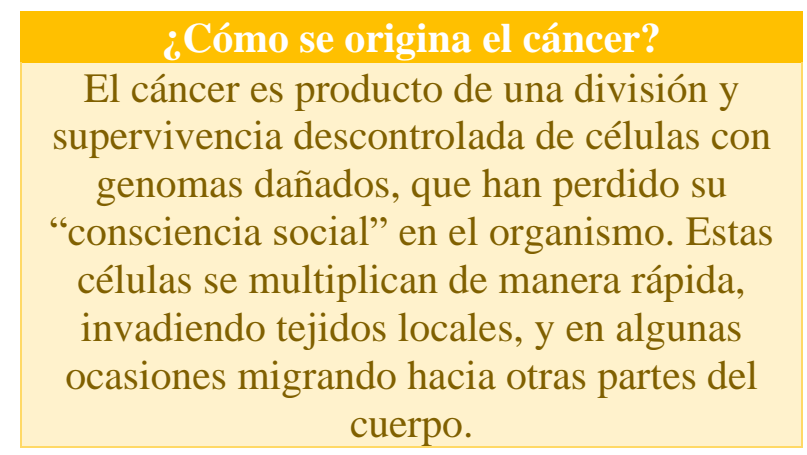

\section{Propiedades Anticancerígenas del Propóleos}

El propóleos de las abejas Apis mellifera inhibe la proliferación de células cancerígenas actuando a diferentes niveles. Por un lado, causa un arresto del ciclo celular, esto es, no permite que la célula cancerígena complete su ciclo de vida, que culmina con la mitosis (división celular). Por otro lado, activa el proceso de muerte 
celular programada (apoptosis). También tiene la capacidad de inhibir la migración de células tumorales e interferir con la creación de nuevos vasos sanguíneos (angiogénesis), un proceso que contribuye a la diseminación y supervivencia de células cancerígenas. Todos estos procesos están controlados por múltiples vías intracelulares y algunos de ellos están interconectados, como es el caso del arresto del ciclo celular e inducción de apoptosis. También es importante mencionar que mientras el propóleos inhibe el crecimiento de células cancerígenas, no afecta la proliferación de células normales.

El ciclo celular, que es el ciclo de vida de una célula, es un proceso controlado, que consiste de varias fases, durante las cuales la célula crece (fases G1, G2), replica su genoma (fase S) y finalmente se divide (fase M, mitosis). La transición entre fase y fase está regulada por acción de ciclinas que se unen a y activan a proteínas quinasas dependientes de ciclinas (Cdks). La acción de estos complejos ciclina-Cdk sobre otras moléculas dentro de la célula conduce a transiciones ordenadas entre las distintas fases del ciclo celular en los momentos apropiados. En las células cancerígenas este proceso está alterado, de modo que la célula se divide de manera descontrolada, ignorando señales externas y a pesar de que su genoma pueda estar dañado (Alberts et al., 2008).

El propóleos afecta distintas moléculas reguladoras del ciclo celular en las células tumorales, como ciclina $\mathrm{D}, \mathrm{Cdk} 2 / 4 / 6$ e inhibidores de Cdks, induciendo un arresto en distintas fases del ciclo celular. El arresto puede ocurrir en las fases G2/M, G0/G1 y en algunas ocasiones, en la fase S; sin embargo, el resultado final es el mismo: se logra impedir que la célula complete su ciclo celular y se divida (Figura 1). Tomando en cuenta la complejidad de la constitución química del propóleos, la variación de su perfil químico en función de la región geográfica de la que proviene y temporada de recolección, y también las diferencias genéticas entre células tumorales de distintos tipos de cáncer, no es sorprendente encontrar que el arresto del ciclo celular suceda en distintas fases para distintas células (Forma y Bryś 2021).

La muerte celular programada, también conocida como apoptosis, es un proceso altamente regulado que ocurre en respuesta a condiciones tanto fisiológicas (destrucción celular programada durante el desarrollo embrionario, etc.) como patológicas (muerte celular en respuesta a hipoxia, daños al ADN, infarto al miocardio, etc.). La apoptosis puede ser activada ya sea por la vía extrínseca o por la vía intrínseca. En la vía extrínseca, el evento que desencadena el proceso de apoptosis es la interacción de receptores de muerte (situados en la superficie de la célula) con moléculas específicas, externas a la célula. En la vía intrínseca, el evento desencadenante ocurre dentro de la célula: un aumento en la permeabilidad de la membrana de las mitocondrias, conduce a la liberación de la molécula citocromo $\mathrm{C}$ desde ellas hacia el citoplasma. La vía extrínseca a su vez puede reclutar (activar) a la vía intrínseca. Como resultado de la activación de una o ambas vías, se activan enzimas proteolíticas (caspasas), que rompen distintas moléculas dentro de la célula; moléculas que mantienen la estructura y el metabolismo celular, afectando la integridad del núcleo, el ciclo celular e induciendo los cambios morfológicos característicos de la apoptosis. La evasión de apoptosis por parte de las células es uno de los mecanismos principales que causan su transformación maligna a cáncer (Wong 2011).

El propóleos induce apoptosis en células cancerígenas a través de la activación tanto de la vía extrínseca, como de la vía intrínseca de apoptosis (Figura 1). En algunas células el propóleos provoca la alteración del potencial de membrana mitocondrial, en otras activa a las caspasas 3/8/9; en muchos casos también activa la expresión de genes pro-apoptóticos (Bax, Bad), p-53, inhibe genes anti-apoptóticos (Bcl-xL, Bcl-2) e incrementa la concentración intracelular de especies reactivas de oxígeno. Además, el propóleos también 
induce autofagia en células de cáncer de mama, un proceso de digestión/muerte celular relacionado con la apoptosis (Forma y Bryś 2021).

Angiogénesis es el proceso de creación de nuevos vasos sanguíneos. Por si solo no es un proceso patológico, sin embargo, las células cancerígenas, al estarse dividiendo más rápidamente, y necesitar de un constante suministro de sangre, liberan sustancias químicas que estimulan la angiogénesis localizada. La creación de vasos sanguíneos nuevos dentro de los tumores no sólo es una forma de obtener oxígeno y nutrientes, sino también crea una ruta de escape, a través de la cual las células tumorales pueden diseminarse hacia otras partes del cuerpo. La liberación del factor de crecimiento endotelial vascular (VEGF) es un mediador clave de angiogénesis en cáncer. Se ha visto que el propóleos tiene la capacidad de inhibir la producción de VEGF por las células cancerosas, y además también disminuye la producción de metaloproteinasas 2 y 9 (MMP2, MMP9) (Chiu et al. 2020; Forma y Bryś 2021). Éstas últimas son proteínas peptidasas que degradan componentes de la matriz extracelular, ayudando a crear espacio para la migración de células endoteliales que formarán los vasos sanguíneos, y también favoreciendo la metástasis (Figura 1).

Metástasis es un proceso complejo que lleva a la aparición de tumores secundarios localizados en tejidos distantes del sitio del tumor primario. Numerosos estudios han confirmado que el propóleos inhibe la migración e invasión de células cancerígenas de distintos tipos. A nivel de célula el propóleos afecta a distintas vías de señalización intracelulares, que son como vías de comunicación interna, entre ellas las vías MAPK (proteínas quinasas activadas por mitógenos) y PI3K/AKT. También se ha visto que el propóleos inhibe la expresión de Wnt2 y FAK (quinasa de adhesión focal), proteínas implicadas en la promoción del crecimiento tumoral y migración (Figura 1) (Chiu et al. 2020; Forma y Bryś 2021).

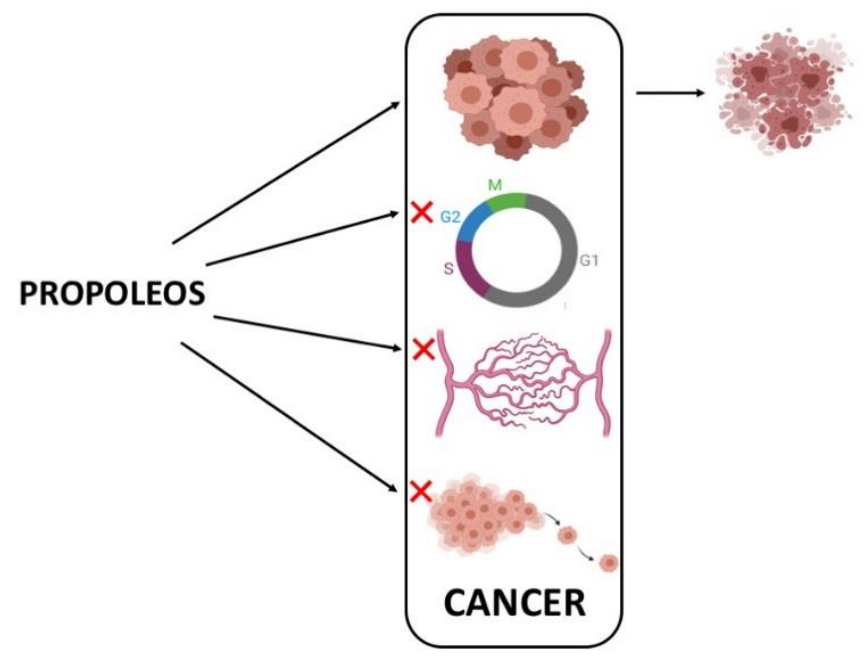

Figura 1: El cáncer se caracteriza por una proliferación descontrolada de células, que evaden la muerte celular programada, inducen la creación de nuevos vasos sanguíneos y en algunas ocasiones migran e invaden tejidos sanos. El propóleos induce apoptosis y arresto del ciclo celular de las células cancerígenas, inhibe la angiogénesis y la diseminación de células tumorales.

Creado usando BioRender.com 


\section{Conclusiones}

El propóleos es una matriz biológica rica en sustancias químicas con propiedades anti-cancerígenas. Inhibe la proliferación y migración de células cancerígenas de manera selectiva, sin dañar a células normales. Arresta a las células tumorales en diferentes partes de su ciclo celular, al mismo tiempo que induce apoptosis. Esto convierte al propóleos en una alternativa atractiva para el potencial desarrollo de fármacos anticancerígenos. Una de las limitantes para producir medicamentos a base del propóleos, es la gran variación en el contenido y cantidad relativa de los compuestos químicos que lo componen, que depende de la zona geográfica de recolección, el clima y la estación del año. Sin embargo, los químicos individuales contenidos en el propóleos pudieran representar una buena alternativa para desarrollar nuevas terapias anticancerígenas. La buena noticia es que por un lado, ya se está haciendo investigación de estos compuestos e incluso se han encontrado interacciones sinérgicas entre ellos, y por otro lado, se siguen descubriendo compuestos químicos nuevos contenidos en el propóleos, algunos con un gran potencial terapéutico.

\section{Referencias}

Alberts B, Johnson A, Lewis J, Raff M, Roberts K, Walter P. 2008. Molecular biology of the cell 5th edition. Garland Science. Taylor \& Francis Group, LLC.

Biodiversity informatics in action: identification and monitoring of bee species using ABIS. Proc 15th Int Symp Informatics for Environmental Protection; 2001: ETH Zurich.

Castaldo S, Capasso F. 2002. Propolis, an old remedy used in modern medicine. Fitoterapia. 73:S1-S6.

Chiu H-F, Han Y-C, Shen Y-C, Golovinskaia O, Venkatakrishnan K, Wang C-K. 2020. Chemopreventive and Chemotherapeutic Effect of Propolis and Its Constituents: A Mini-review. Journal of Cancer Prevention. 25(2):70.

Cornara L, Biagi M, Xiao J, Burlando B. 2017. Therapeutic Properties of Bioactive Compounds from Different Honeybee Products. Front Pharmacol. 8:412.

Forma E, Bryś M. 2021. Anticancer Activity of Propolis and Its Compounds. Nutrients. 13(8):2594.

Huang S, Zhang CP, Wang K, Li GQ, Hu FL. 2014. Recent advances in the chemical composition of propolis. Molecules. 19(12):19610-19632.

Kritsky G. 2017. Beekeeping from antiquity through the middle ages. Annual Review of Entomology. 62:249-264.

Kuropatnicki AK, Szliszka E, Krol W. 2013. Historical aspects of propolis research in modern times. Evid Based Complement Alternat Med. 2013:964149.

Medic-Saric M, Rastija V, Bojic M, Males Z. 2009. From functional food to medicinal product: systematic approach in analysis of polyphenolics from propolis and wine. Nutr J. 8:33.

Ratnieks FL, Shackleton K. 2015. Does the waggle dance help honey bees to forage at greater distances than expected for their body size? Frontiers in Ecology and Evolution. 3:31.

Simone-Finstrom M, Spivak M. 2010. Propolis and bee health: the natural history and significance of resin use by honey bees. Apidologie. 41(3):295-311.

Sung H, Ferlay J, Siegel RL, Laversanne M, Soerjomataram I, Jemal A, Bray F. 2021. Global cancer statistics 2020: GLOBOCAN estimates of incidence and mortality worldwide for 36 cancers in 185 countries. CA: a cancer journal for clinicians. 71(3):209-249.

Wong RS. 2011. Apoptosis in cancer: from pathogenesis to treatment. Journal of Experimental \& Clinical Cancer Research. 30(1):1-14.

Cómo citar este artículo: Lipovka, Y., Alday, E., \& Velázquez, C. (2021). El propóleos, una Resina Biológica con Propiedades Curativas. INVURNUS, 16 (1), 1-7. 